\title{
Impacts of Effective Communication towards Performance of Construction Organization
}

\author{
Mohammed Isah Leje ${ }^{1}$, Mohammed Alhaji Kasimu ${ }^{2}$, Asimiyu Folaranmi Kolawole ${ }^{2}$ \\ ${ }^{2}$ The Federal Polytechnic Bida \\ KM 1.5, Doko Road, Bida, Niger State, Nigeria
}

DOl: $10.22178 /$ pos.49-4

LCC Subject Category: H1-99

Received 28.06.2019

Accepted 30.08.2019

Published online 31.08.2019

Corresponding Author:

Mohammed Isah Leje

isahleje5@yahoo.com

(C) 2019 The Authors. This article is licensed under a Creative Commons Attribution 4.0 License (c) (1)

\begin{abstract}
The purpose of this study is to examine the significant impacts of effective communication towards the performance of the construction organization. The objectives of the study include to identify impacts of effective communication and evaluate the degree of agreement to which effective communication influence construction organization from construction contractors and consultants' viewpoint. A sample of 200 construction contractors and consultants were randomly selected from the Bureau of Public Procurement (BPP) database, out of which the responses rates received were $160(80 \%)$. Data analysis include Relative Importance Index (RII) for ranking comparison among the construction professionals on a scale range from 1-5 for rating their responses. Kendall's coefficient of concordance was used to evaluate the degree of agreement between construction professionals related to the ranking of each group of the practices. The results of RII revealed that improve productivity in the organization, reduce project delay, better safety precautions on construction sites, better use of materials and equipment and improve professional commitment to the organization are the top five impacts of effective communication towards the performance of construction organization. The results of Kendall's coefficient of concordance revealed that a high agreement between construction professionals occurred in the ranking of the impacts of effective communication towards the performance of the construction organization. The findings revealed that effective communication help to facilitate better understanding among all parties in the construction organization. It was recommended that stakeholders in the construction organization should adopt the use of effective communication tools and instruments for organizational performance.
\end{abstract}

Keywords: construction organization; construction professionals; effective communication; construction performance.

\section{INTRODUCTION}

The performance of construction organization constitutes an effective and efficient project delivery which has a great influence on industrial growth and production of infrastructure necessary to improve the living standards of a country [1]. However, for such to occur, the construction organization depends on the quality of relationships between the clients, professionals, contractors, subcontractors, technical workers and regulatory bodies [5]. This correlation is basically due to the fact that all the various stages of construction rely on the construction parties transferring appropriate and relevant information to planned, scheduled and controlled a project [12]. This according to $[4,9]$ emphasized that construction is an information-intensive industry since hun- dreds and thousands of piece of information need to be transferred and exchanged between various departments/units during the project life-cycle. Therefore, each department/unit in construction organization is responsible for disseminating the related information needed to formulate effective communication.

An effective communication plays a vital role in all stages of construction project which involves the exchange and flow of information and ideas from one person to another [2, 8]. Authors [9] asserted that as a construction project unfolds, communication occur in various directions which revolves from the organization to top management (upward communication), within the project teams (lateral communication), from superior to subordinate (downward communication) 
and from subordinates to superior (horizontal communication). For instance, an architect prepares a general outline of client requirements after carrying out feasibility studies with the other consultants and communicates it to the rest of the members of the design team for collective action. As soon as the client approval is obtained, the architect and engineer start preparing the working drawings, schedules and specifications and at the same time seeking the opinion of the quantity surveyor who sees to the cost implication of the project to see if the project design is still within the approved budget. This goes on to all stages until completion of a project is achieved. Despite these roles, there seems little doubt that effective communication plays a vital role in the performance of construction organization. Hence, there is need for an extensive studies to be conducted on the impacts of effective communication towards performance of construction organization, taking into accounts construction contractors and consultants' views.

Accordingly, this study first presents the findings from relevant literatures in relation to effective communication. Next, the research methodology followed by discussions through the findings presented on the impacts of effective communications from construction contractors and consultants' viewpoint. The final section summarizes the conclusion derived from the research findings and present recommendation.

Communication plays a vital role in all stages of construction project delivery, from design stage through production, organization and management. Most of the researchers agreed that effective communication in construction organization could go a long way to deliver projects of desired quality, cost and on schedule time $[13,7,8,12$, 18]. Therefore, the impacts of effective communication in the construction industry cannot be under-rated as they have the potential of eliminating inefficiencies arising from poorly constructed projects. For these reason, [12] acknowledged that if there is an effective communication between project team, accurate information will be quickly disseminated and consensus decisions achieved. Thus, prevent some ripple effects that may have been caused from misconception.

Authors [13] investigated communication in the construction organization and found out that by adopting effective communication during project delivery, it can help in meeting the predeter- mined cost and time of the project. Researcher [18] revealed that effective communication can help to achieve better time and cost management in producing a successful project. Authors [7] stated that lack of effective communication in the construction organization within a bilingual workforce raises a number of safety issues. Therefore, this implies that effective communications are geared towards performance of construction organization.

From the foregoing studies, the impacts of an effective communication in construction organization were identified, which were related to impacts on organizational efficiency and effectiveness. However, the study is geared towards determining the most significant impacts based on construction contractors and consultants' views. Hence, it is the gap of determining the most significant impacts of effective communication towards construction organization performance that is the motivation for this study.

\section{RESEARCH METHODOLOGY}

In order to collect the data, this study adopted qualitative approach before conducting quantitative analysis. The qualitative data of the study were based on a literature review and consisted of 20 impacts of effective communication which have been examined by previous researchers. A preliminary study was first carried out on a small scale of respondents to ensure clarity and avoidance of double barrel questions. Four of construction experts having strong background of construction business participated in the preliminary study. In total, 14 impacts of an effective communication as shown in Table 1 , were selected by experts as the impacts of effective communication in Nigeria. Accordingly, the operational measures of these impacts were categorized into two groups of impacts on organizational efficiency and effectiveness. These impacts were used to construct a structured questionnaire for the pilot study. A total of thirty construction contractors and consultants participated in the pilot study. The respondents suggested few changes to the questionnaire regarding the wordings of the questions. The questionnaire was then modified based on the feedback, before it was finally used at the data collection stage. 
Table 1 - Impacts of effective communication towards performance of construction organization

\begin{tabular}{|l|l|c|}
\hline \multicolumn{1}{|c|}{ Impacts } & Authors \\
\hline & A. Impacts on organizational efficiency & \\
\hline A1 & Improve productivity of an organization & {$[8]$} \\
\hline A2 & Reduce disputes in the organization & {$[6]$} \\
\hline A3 & Minimized accident rates on construction sites & {$[15]$} \\
\hline A4 & Better safety precautions on construction sites $[15]$ \\
\hline A5 & Improve professional commitment to the organization & {$[8]$} \\
\hline A6 & Increase organizational stability and flexibility & {$[18]$} \\
\hline A7 & Improve work quality & {$[18]$} \\
\hline A8 & Reduce project delay & {$[14]$} \\
\hline & B. Impacts on organizational effectiveness & \\
\hline B1 & Improve workmanship & {$[2]$} \\
\hline B2 & Better use of materials and equipment & {$[5]$} \\
\hline B3 & Less supervision & {$[8]$} \\
\hline B4 & Reduce rework from unsatisfactory work done & {$[18]$} \\
\hline B5 & Reduce wastages of construction materials & {$[2]$} \\
\hline B6 & High performance and innovation & {$[17]$} \\
\hline
\end{tabular}

The questionnaire consists of two sections. Section A consist of respondents personal particulars such as; membership of professional bodies, years of experience, academic qualification and numbers of projects executed. In section $B$, each respondent was asked to rate the impact of effective communication on a five-point Likert scale ranging from 1 to 5, where 1 represents "Insignificant" and 5 represent "Very significant".

\section{Sample structures}

A sample of 200 construction contractors and consultants within F. C. T, Abuja was targeted in the survey, comprising 100 each of contractors and consultants randomly drawn from the $\mathrm{Bu}$ reau of Public Procurement (BPP) database. Though, there are several methods of administering a questionnaire survey, direct delivery of the questionnaire by hand was preferred using the members' directory. Table 2 shows a summary of the sample responses of the questionnaire survey. From table 2, the response rates were 80 (80\%) each for contractors and consultants respectively. This was considered adequate for analysis based on the assertion by [10] that the result of a survey could be considered as biased and of little importance if the return rate was lower than $30-40 \%$.

Table 2 - Sample responses of the questionnaire survey

\begin{tabular}{|l|c|c|c|}
\hline \multirow{2}{*}{ Professionals } & \multicolumn{2}{|c|}{ Number of questionnaire } & \multirow{2}{*}{ Percentage returned, \% } \\
\cline { 2 - 3 } & Number administered & Valid for analysis & \\
\hline 1. Contractors & 100 & 80 & 80 \\
\hline 2. Consultants & 100 & 80 & 80 \\
\hline Total & 200 & 160 & \\
\hline
\end{tabular}

\section{Cronbach's Alpha Reliability Test}

Cronbach's Alpha coefficient test is used for evaluating the reliability of the instrument. The measure is considered to be reliable if the value of Cronbach's Alpha coefficient equals or exceeds $0.70[11,16]$. In this study, the values of Cronbach's Alpha Coefficient for the construct ranged from 0.783 to 0.867 . Since these values were more than 0.7 , the entire construct as well as the variables was believed to have demonstrated a good reliability to be measured on the same latent trait and scale.

\section{RESULTS AND DISCUSSION}

The data was analyzed using the Relative Importance Index (RII) comparison of ranking among the construction contractors and consultants. 
The performance of each parameter was evaluated based on the importance weighting and the proposed efficiency of each variable. From the responses, RII was calculated using the formula below (1):

$$
R I I=\frac{5 n_{1}+4 n_{2}+3 n_{3}+2 n_{4}+n_{5}}{5\left(n_{1}+n_{2}+n_{3}+n_{4}+n_{5}\right)},
$$

where $\mathrm{n}_{1}$ represents the number of respondents who answered 'very significance', $\mathrm{n}_{2}$ represents the number of respondents who answered 'significance', $\mathrm{n}_{3}$ represents the number of respondents who answered 'moderately significance', $\mathrm{n}_{4}$ represents the number of respondents who answered 'less significance', $\mathrm{n}_{5}$ represents the number of respondents who answered 'insignificance'

The results of the RII from Table 3 shows that reduce project delay are ranked topmost by contractors and second by consultants. Also, improve productivity in the organization was ranked first by the consultants and second by contractors. Better safety precaution on construction sites was ranked third by contractors and consultants. Better use of materials and equipment was also ranked third by consultants and fourth by contractors. Also, improve professional commitment to the organization was ranked fourth by contractors and fifth by consultants. Improve workmanship was ranked sixth by contractors and fifth by consultants.

Table 3 - RII and ranks of contractors and consultants' responses

\begin{tabular}{|l|l|l|l|l|l|l|}
\hline \multicolumn{1}{|c|}{ Construction organizations } & \multicolumn{3}{c|}{ Contractors } \\
\multicolumn{1}{|c|}{ Impacts } & S & \multicolumn{1}{c|}{ RII } & R & S & \multicolumn{1}{c|}{ RII } & R \\
\hline Impacts on organizational efficiency & & & & & & \\
\hline Improve productivity in the organization & 262 & 0.655 & 2 & 235 & 0.588 & 1 \\
\hline Reduce disputes in the organization & 245 & 0.613 & 9 & 220 & 0.550 & 8 \\
\hline Minimized accident rates on construction sites & 248 & 0.620 & 8 & 210 & 0.525 & 10 \\
\hline Better safety precautions on construction sites & 260 & 0.650 & 3 & 225 & 0.563 & 3 \\
\hline Improve professional commitment to the organization & 255 & 0.638 & 4 & 223 & 0.558 & 5 \\
\hline Increase organizational stability and flexibility & 225 & 0.563 & 11 & 200 & 0.500 & 12 \\
\hline Improve work quality & 240 & 0.600 & 10 & 218 & 0.545 & 9 \\
\hline Reduce project delay & 265 & 0.663 & 1 & 230 & 0.575 & 2 \\
\hline Impacts on organizational effectiveness & & & & & & \\
\hline Improve workmanship & 252 & 0.630 & 6 & 223 & 0.558 & 5 \\
\hline Better use of materials and equipment & 255 & 0.638 & 4 & 225 & 0.563 & 3 \\
\hline Less supervision & 250 & 0.625 & 7 & 223 & 0.558 & 5 \\
\hline Reduce rework from unsatisfactory work done & 225 & 0.563 & 11 & 207 & 0.518 & 11 \\
\hline Reduce wastages of construction materials & 220 & 0.550 & 13 & 195 & 0.488 & 13 \\
\hline High performance and innovation & 215 & 0.538 & 14 & 190 & 0.475 & 14 \\
\hline
\end{tabular}

Notes: S - Sum of responses; RII - Relative Importance Index; R - Ranking

Consequently, in order to have a general agreement in the ranking of all the impacts, Rank Agreement Factor (RAF) and PRAF was used to quantitatively measure the agreement in the importance ranking among the contractors and consultants. This is in line with the suggestion by [3].

$$
\begin{aligned}
& R A F=\frac{\varepsilon Q A E B}{N}, \\
& R A F=\frac{R A F_{\text {max }}-R A F_{i}}{R A F_{\text {max }}} \times 100,
\end{aligned}
$$

where $\mathrm{RAF}_{\max }$ - maximum RAF, N - total number of impacts, and EQEAB - sum of the order of ranking by contractors and consultants.

The RAF can be $>1$, with a higher factor implying greater disagreement while a RAF zero implies perfect agreement [3]. The results of RAF are shown in the fifth column of Table 4 . For 14 impacts of effective communication, RAFmax is 2.000 . 
Table 4 - PRAF of all the contractors and consultants

\begin{tabular}{|l|l|l|l|l|l|l|}
\hline \multicolumn{1}{|c|}{ Impacts } & Ctr & Csl & Sum & RAF & PRAF $\%$ & R \\
\hline Improve productivity in the organization & 2 & 1 & 3 & 0.214 & 89.30 & 1 \\
\hline Reduce project delay & 1 & 2 & 3 & 0.214 & 89.30 & 1 \\
\hline Better safety precautions on construction sites & 3 & 3 & 6 & 0.429 & 78.55 & 3 \\
\hline Better use of materials and equipment & 4 & 3 & 7 & 0.500 & 75.00 & 4 \\
\hline Improve professional commitment to the organization & 4 & 5 & 9 & 0.643 & 67.85 & 5 \\
\hline Improve workmanship & 6 & 5 & 11 & 0.786 & 60.7 & 6 \\
\hline Less supervision & 7 & 5 & 12 & 0.857 & 57.15 & 7 \\
\hline Reduce disputes in the organization & 9 & 8 & 17 & 1.214 & 39.30 & 8 \\
\hline Minimized accident rates on construction sites & 8 & 10 & 18 & 1.286 & 35.70 & 9 \\
\hline Improve work quality & 10 & 9 & 19 & 1.357 & 32.15 & 10 \\
\hline Reduce rework from unsatisfactory work done & 11 & 11 & 22 & 1.571 & 21.45 & 11 \\
\hline Increase organizational stability and flexibility & 11 & 12 & 23 & 1.643 & 17.85 & 12 \\
\hline Reduce wastages of construction materials & 13 & 13 & 26 & 1.857 & 7.15 & 13 \\
\hline High performance and innovation & 14 & 14 & 28 & 2.000 & 0.00 & 14 \\
\hline
\end{tabular}

Notes: RAF - ranking agreement factor; PRAF - percentage ranking agreement factor.

From the results of the PRAF in Table 4, top five impacts of an effective communication towards performance of construction organization are improve productivity in the organization, reduce project delay, better safety precautions on construction sites, better use of materials and equipment and improve professional commitment to the organization. These impacts are interrelated and have direct outcomes on the performance of construction organization. The results show you improve productivity in the organization as the topmost impacts of an effective communication. This agrees with the contention of [8] that effective communication may influence the productivity of an organization as it is managed by all departments/units in the organization. Reduce project delay was also revealed as the topmost impacts, which is in line with the opinion of [14] that effective communication are related to complete a project within time. The result also show you better safety precautions on construction sites as a significant impacts of an effective communication. This was corroborated by [15] asserting that effective communication results to satisfactory health and safety precautions on construction sites. Better use of materials and equipment was also revealed as one of the impacts of effective communication towards performance of construction organization. $\mathrm{Au}-$ thor [5] acknowledged that effective communication brings about prudent use of resources in the construction organization. Improve professional commitment to the organization was also ranked as one of the significant impacts of an effective communication, which agrees with the contention of [8] that in order to foster professionalism in the construction organization effective communication must be brought to the attention of all the parties involved in a project.

\section{Kendall's Coefficient of Concordance}

To evaluate the degree of agreement to which effective communication influence performance of construction organization, two hypotheses was formulated. To test this hypotheses written below, Kendall's coefficient of concordance (W) was performed to estimate the degree of agreement between construction contractors and consultant' views related to the ranking of each group of the impacts, and whether this agreement is statistically significant. The range of the value $\mathrm{W}$ is between 0 and 1 (1 represents the perfect agreement between construction contractors and consultants, while 0 represents completely no agreement between construction contractors and consultants).

H1. There is no degree of agreement between construction contractors and consultants towards the ranking of the impact of effective communication on organizational efficiency.

This category consist of eight impacts of effective communication. The results from Table 5, indicates that Kendall's coefficient is found to be 0.952 and the p-value is 0.000 which is below the threshold of 0.05 significance level. In conclusion, there is a significant and strong degree of agreement between construction contractors and consultants towards the ranking of the impact of effective communication on organizational efficiency. 
Table 5 - Impacts on organizational efficiency

\begin{tabular}{|l|r|r|r|r|r|r|}
\hline \multicolumn{1}{|c|}{ Construction organizations } & \multicolumn{3}{c|}{ Contractors } & \multicolumn{3}{c|}{ Consultants } \\
\hline \multicolumn{1}{|c|}{ Impacts } & S & RII & R & S & RII & R \\
\hline Impacts on organizational efficiency & & & & & & \\
\hline Improve productivity in the organization & 262 & 0.655 & 2 & 235 & 0.588 & 1 \\
\hline Reduce disputes in the organization & 245 & 0.613 & 9 & 220 & 0.550 & 8 \\
\hline Minimized accident rates on construction sites & 248 & 0.620 & 8 & 210 & 0.525 & 10 \\
\hline Better safety precautions on construction sites & 260 & 0.650 & 3 & 225 & 0.563 & 3 \\
\hline Improve professional commitment to the organization & 255 & 0.638 & 4 & 223 & 0.558 & 5 \\
\hline Increase organizational stability and flexibility & 225 & 0.563 & 11 & 200 & 0.500 & 12 \\
\hline Improve work quality & 240 & 0.600 & 10 & 218 & 0.545 & 9 \\
\hline Reduce project delay & 265 & 0.663 & 1 & 230 & 0.575 & 2 \\
\hline Kendall's coefficient & 0.952 & & & & & \\
\hline Sig. & 0.000 & & & & & \\
\hline
\end{tabular}

H2. There is no degree of agreement between construction contractors and consultants towards the ranking of the impact of effective communication on organizational effectiveness.

This category includes six impacts of an effective communication. The results from Table 6 , indicates that Kendall's coefficient is found to be
0.993 and the p-value is 0.000 which is below the threshold of 0.05 significance level. In conclusion, there is a significant and strong degree of agreement between construction contractors and consultants towards the ranking of the impact of effective communication on organizational effectiveness.

Table 6 - Impacts on organizational effectiveness

\begin{tabular}{|c|c|c|c|c|c|c|}
\hline Construction organizations & \multicolumn{3}{|c|}{ Contractors } & \multicolumn{3}{|c|}{ Consultants } \\
\hline Impacts & $\mathrm{S}$ & RII & $\mathrm{R}$ & $\mathrm{S}$ & RII & $\mathrm{R}$ \\
\hline Impacts on organizational effectiveness & & & & & & \\
\hline Improve workmanship & 252 & 0.630 & 6 & 223 & 0.558 & 5 \\
\hline Better use of materials and equipment & 255 & 0.638 & 4 & 225 & 0.563 & 3 \\
\hline Less supervision & 250 & 0.625 & 7 & 223 & 0.558 & 5 \\
\hline Reduce rework from unsatisfactory work done & 225 & 0.563 & 11 & 207 & 0.518 & 11 \\
\hline Reduce wastages of construction materials & 220 & 0.550 & 13 & 195 & 0.488 & 13 \\
\hline High performance and innovation & 215 & 0.538 & 14 & 190 & 0.475 & 14 \\
\hline Kendall's coefficient & 0.993 & & & & & \\
\hline Sig. & 0.000 & & & & & \\
\hline
\end{tabular}

The overall results of hypotheses testing revealed that a high agreement between construction contractors and consultants occurred in the ranking of the impacts of effective communication related to organizational efficiency and effectiveness. This was confirmed by high Kendall's coefficient obtained within each category.

\section{CONCLUSION}

Drawn from the results that shows five topmost impacts of effective communication towards performance of construction organization, it re- vealed that the most significant impacts of an effective communication were common in organizational efficiency. Furthermore, the ranking of improve productivity of an organization and reduction of project delay as the topmost impacts indicates that construction organization were influenced by effective communication. This confirms the perceived low performance of construction organization. In view of the above, it was recommended that stakeholders in the construction organization should adopt the use of effective communication tools and instruments for organizational performance. 


\section{REFERENCES}

1. Abu Bakar, A., Tabassi, A., Razak, A., \& Yusof, M. (2012). Key Factors Contributing to Growth of Construction Companies: A Malaysian Experience. World Applied Sciences Journal, 19(9), 12951304.

2. Aiyewalehinmi, E. O. (2013). Factors Analysis of Communication in the Construction Industry. International Journal of Engineering and Science, 2(10), 49-57.

3. Chan, D., \& Kumaraswamy, M. (2002). Compressing construction durations: lessons learned from Hong Kong building projects. International Journal of Project Management, 20(1), 23-35. doi: 10.1016/s0263-7863(00)00032-6

4. Gaith, F. (2012). Application and efficacy of information technology in construction industry. Scientific Research and Essays, 7(38). doi: 10.5897/sre11.955

5. Jimoh, R. (2012). Improving Site Management Practices in the Nigerian Construction Industry: The Builders' Perspective. Ethiopian Journal of Environmental Studies and Management, 5(4). doi: 10.4314/ejesm.v5i4.5

6. Mitkus, S., \& Mitkus, T. (2014). Causes of Conflicts in a Construction Industry: A Communicational Approach. Procedia - Social and Behavioral Sciences, 110, 777-786. doi: 10.1016/j.sbspro.2013.12.922

7. Ochieng, E. G., \& Price, A. D. F. (2010). Managing cross-cultural communication in multicultural construction project teams: The case of Kenya and UK. International Journal of Project Management, 28(5), 449-460. doi: 10.1016/j.ijproman.2009.08.001

8. Olanrewaju, A., Tan, S. Y., \& Kwan, L. F. (2017). Roles of Communication on Performance of the Construction Sector. Procedia Engineering, 196, 763-770. doi: 10.1016/j.proeng.2017.08.005

9. Onyegiri, I., \& Nwachukwu, C. (2011). Information and communication technology in the construction industry. American Journal of Scientific and Industrial Research, 2(3), 461-468. doi: 10.5251/ajsir.2011.2.3.461.468

10. Oyedele, L. O., \& Tham, K. W. (2007). Clients' assessment of architects' performance in building delivery process: Evidence from Nigeria. Building and Environment, 42(5), 2090-2099. doi: 10.1016/j.buildenv.2005.06.030

11. Pallant, J. (2011). A Step by Step Guide to Data Analysis Using SPSS Programme: SPSS Survival Manual (4th ed.). Sydney: Allen and Unwin.

12. Park, J.-G., \& Lee, J. (2014). Knowledge sharing in information systems development projects: Explicating the role of dependence and trust. International Journal of Project Management, 32(1), 153-165. doi: 10.1016/j.ijproman.2013.02.004

13. Rahman, A., Memon, A., \& Latif, Q. (2012). Time and Cost Performance of Construction Projects in Southern and Central Regions of Peninsular Malaysia. Retrieved from https://core.ac.uk/download/pdf/12008294.pdf

14. Soliman, E. (2017). Communication Problems Causing Governmental Projects Delay: Kuwait Case Study. International Journal of Construction Project Management, 9(1), 1-18.

15. Spillane, J., \& Oyedele, L. O. (2013). Strategies for effective management of health and safety in confined site construction. Construction Economics and Building, 13(4), 50-64. doi: 10.5130/ajceb.v13i4.3619

16. Tabachnick, B. G. \& Fidell, L. S. (2013). Using Multivariate Statistics (6th ed.) Boston: Allyn \& Bacon. Zekavat, P. R., Moon, S., \& Bernold, L. E. (2014). Performance of short and long range wireless communication technologies in construction. Automation in Construction, 47, 50-61. doi: 10.1016/j.autcon.2014.07.008 
17. Zekavat, P. R., Moon, S., \& Bernold, L. E. (2014). Performance of short and long range wireless communication technologies in construction. Automation in Construction, 47, 50-61. doi: 10.1016/j.autcon.2014.07.008

18. Zulch, B. (2014). Communication: The Foundation of Project Management. Procedia Technology, 16, 1000-1009. doi: 10.1016/j.protcy.2014.10.054 